\title{
Investigation of Gas Nitriding Effect on Damping Ratio of Steel 1.7225 and Cutting Vibration of Indexable End Mill Made from It During the Straight Groove
}

\author{
Abbas Rahi ( $\nabla$ a_rahi@sbu.ac.ir) \\ Shahid Beheshti University https://orcid.org/0000-0002-7123-1741 \\ Mahdi Hosseinpour \\ Shahid Beheshti University, \\ Behrouz Mahdikhani \\ Hold Research and Development Unit \\ Elham Inanloo \\ Tehran University
}

\section{Research Article}

Keywords: end-mill, vibration, peak, nitriding, damping, RMS

Posted Date: November 9th, 2021

DOI: https://doi.org/10.21203/rs.3.rs-981470/v1

License: (c) (i) This work is licensed under a Creative Commons Attribution 4.0 International License.

Read Full License 


\section{Abstract}

End-milling is a cutting technology that removes material from machined workpieces by end mill and is widely used to manufacture parts. Moreover, this process is prone to vibration due to low stiffness. Also, nitriding is a surface hardening process with lots of effects on mechanical properties. This study investigated the effect of gas nitriding on a nitrided end mill in comparison with an unnitrided end mill and showed significant improvement in vibration peak and RMS during end milling. To clarify the reason for this improvement this article carried out a modal test to show how nitriding affected the natural frequency and damping ratio of the nitrided and unnitrided samples and showed that tool rigidity remained the same while damping ratio increased so we claimed nitriding improved damping ratio without change of tool rigidity. For verifying this claim we modeled, meshed, and analyzed for obtaining tool natural frequency both for nitrided and unnitrided tool and compared with extracted natural frequencies from each tool FFT diagram during straight grooving. We showed that the natural frequencies were the same with less than 3 percent change so we concluded that nitriding led to better tool performance by increasing the damping ratio without any significant change in the tool stiffness.

\section{Introduction}

Production lines are greedily looking to add new scientific properties to their products to differentiate their products from competitors and get a larger piece of the market and nitriding is considered as the economical case with a lot of potential for this purpose. Nitriding is described as a thermochemical surface treatment in which nitrogen is transformed from an ammonia atmosphere into steel below eutectoid temperature [1]. Because of the low solubility of nitrogen in ferrite, the nitrides precipitate during the nitriding process [2]. This precipitation creates a compound layer and an underlying diffusion zone near the surface of the steel after nitriding. This compound layer also known as the white layer consists of nitrides and can improve mechanical properties [3]. Beregovenko et al. [4] investigated the effect of nitriding on steel $\mathrm{Ck} 45$ under different nitriding conditions and demonstrated that damping of $\mathrm{Ck} 45 \mathrm{can}$ be improved up to six times in the best nitriding parameter combination. Therefore, nitrided tools can have better vibration conditions in comparison to conventional tools. Tomonori et al. [5] studied on mechanical properties and corrosion resistance of nitrided austenite stainless steel and showed significant improvement in it. He demonstrated that yield stress almost remained identical to the previous level while ultimate strength increased up to a maximum level after nitriding and pitting resistance improved. Hung et al. [6] investigated SACM 645 Steel specimens with different substrate hardness under gas nitriding and showed increases in wear resistance for the nitrided specimens. He also improved the fatigue limit by 44 percent by 96 hours of gas nitriding. Valdes et al. [7] studied contact fatigue behavior of nitrided AISI $316 \mathrm{~L}$ steels and the results showed that the thinnest thickness of the nitrided layer exhibits better resistance to standing contact fatigue.

The machining industries are facing a great challenge to achieve high quality, good surface finish, and high material removal rate to economizing in machining [8]. Tool vibration is one of the key factors in increasing surface quality and productivity so a lot of efforts have been made to control and reduce tool 
vibration in the machining industry [9], [10]. Bashir et al. [11] used the variable pitch method to reduce end mill vibration in end milling and demonstrated that forced vibration was reduced during milling by variable pitch end mill in comparison to equal pitch milling tool. Dombovari et al. [12] investigated the effect of helix angle variation on milling stability and showed that cutting can be done extremely in high depth at high spindle speeds by this method. Hayati and Madoliat [13] proposed an endmill with a core damper fitted inside and used a frictionally damped mechanism to reduce vibration. They showed that because the boundary between the core damper and the body is not separable, the deflection of the tool is hindered by the core damper so this causes a high improvement in tool performance. Yang et al. [14] used two degrees of freedom tuned mass damper to damp the first mode of vibration in the milling process and finally demonstrated that the amplitude of the first mode of vibration reduces up to 80 percent and critical depth of cut doubles by using this method and finally got good accordance between theoretical and experimental results.

In this study, we investigated the effect of gas nitriding on the indexable end mills to show how the nitriding process would affect the milling process. We ran two nitrided and unnitrided tools on CNC and monitored their behavior during machining and found out a significant improvement in tool peaks and RMS. For interpretation of this improvement we carried out a modal test to examine the effect of nitriding on damping ratio and natural frequency and the result showed increasing damping ratio without changing natural frequency a lot. So, we claimed nitriding has affected damping ratio without any sensible impact on tool rigidity and this claim was verified by modeling and calculating of natural frequency for nitrided and unnitrided tools. Besides all overestimation we supposed for a nitrided layer we demonstrated that natural frequency and tool rigidity would increase up to 3 percent which is ignorable and shown improvement is because of the increasing damping ratio.

\section{Experimental Conditions}

To investigate the effect of gas nitriding on the end-milling process we used two commonly used indexable endmills shown in Figure 1. By machining two straight grooves as shown in Figure 2 we compared the effect of nitriding on the tool holder during machining. It should be noted that in both cases we have had the same conditions in terms of run out and overhang and the used material was steel 1.7225 also known as MO40 steel and AISI 4140.

Figure 2 shows the test setup and shows the coordinate system of end milling. End milling of straight grooves was conducted on a LEADWELL CNC milling machine (made by LEADWELL CNC MACHINES MFG.CORP., Taichung City, Taiwan).

the cutting tool was an indexable end-mill with APKT 10 inserts and cutting diameter 20 millimeters, shank diameter 20 millimeters, and total length of 150 millimeters made by the Iranian X-Hold Company. As shown in Figure 1 the tool holder does have three APKT inserts made by the Chinese Hard-stone Company. Our configuration also had a $90 \mathrm{~mm}$ stick-out length for the tool holder with a $0.05 \mathrm{~mm}$ run-out 
in the setup. According to Figure 2, the AC-102-1A sensors were mounted rigidly on the spindle of the milling machine and the workpiece was fixed onto the clamp.

CTS acceleration sensor was used to monitor the dynamic response of end milling operation by a DEWE43 data collector, where the sensor sensitivity was $100 \mathrm{mv} / \mathrm{g}$ and the frequency range was $1-10 \mathrm{KHz}$. The acquired vibration signal was also entered into the computer for further analysis and the sampling frequency was $20000 \mathrm{~Hz}$.

To have a better understanding of signal analysis, the coordinate system of end-milling is shown in Figure 3 where $X, Y$, and $Z$ directions correspond, respectively to the feed direction, perpendicular direction, and the axis of the end mill. The coordinate origin is the intersection point of the axis of the endmill and the bottom machined surface.

we ran CNC by 1000 RPM and $600 \mathrm{~mm} / \mathrm{min}$ by $1 \mathrm{~mm}$ depth of cut by $90 \mathrm{~mm}$ overhang twice for nitrided tool and unnitrided tool to show how nitriding would affect the RMS of vibration in feed, perpendicular and axial directions. The results showed a significant decrease in vibration peaks and RMS for the nitrided tool which will be discussed in the results.

We should note that as much as we lower vibration peaks and RMS amplitude during the process, we would be able to have a better surface quality, less tool wear, increased machining accuracy, and upper productivity so finding a new method would attract a lot of attention from industry and production lines.

It is not obvious whether decreasing vibration peak and RMS is because of increasing tool rigidity or increasing steel damping ratio so we carried out a modal test to make it clear by measuring damping ratio and natural frequency after nitriding. It should be noted that quench and temper and nitriding conditions both for modal test samples and milling tools were the same.

Figure 4 shows two identical samples made from steel 1.7225 by the composition analysis shown in Table 1, both of them quenched and tempered, and only one of them nitrided.

The samples were heat-treated to harden the core by heating up to 860 degrees and keeping it at this temperature for 45 minutes. The process was followed by quenching in agitated 54-degree mineral oil and was washed in hot water and tempered in the air at 275 degrees.

Table 1

Analysis of used steel in the experiments

\begin{tabular}{|llllllll|}
\hline 42CrMo4/1.7225 & $\mathrm{C}$ & $\mathrm{Mn}$ & $\mathrm{Si}$ & $\mathrm{P}$ & $\mathrm{S}$ & $\mathrm{Cr}$ & $\mathrm{Mo}$ \\
\cline { 2 - 7 } & 0.398 & 0.85 & 0.33 & 0.016 & 0.003 & 0.90 & 0.160 \\
\hline
\end{tabular}

As shown in Figure 5 we hanged the samples on the shown structure and carried out the modal test to determine natural frequency and damping ratio for the samples to find out how nitriding affected these two factors. 
It should be noted that we did this test in the thin $(6 \mathrm{~mm})$ direction and by different impact locations and sensor installation locations because in this direction we had a higher ratio for nitrided depth to the overall depth and this would be more rational to be chosen for nitriding effect investigation.

The modal test was carried out by different sensor installation locations and then we extracted the Acceleration frequency spectrum diagram for each case as shown in Figure 6 and Figure 7. The resultant natural frequencies and damping ratios are shown in Table 2.

Table 2

Results of the modal test in thin direction

\begin{tabular}{|lllllll|}
\hline Number & $\begin{array}{l}\text { impact } \\
\text { location }\end{array}$ & $\begin{array}{l}\text { sensor } \\
\text { installation } \\
\text { location }\end{array}$ & \multicolumn{2}{l}{ unnitrided sample } & \multicolumn{2}{l|}{ nitrided sample } \\
\cline { 5 - 7 } & & $\begin{array}{l}\text { Natural } \\
\text { Frequency } \\
(\mathbf{H z})\end{array}$ & $\begin{array}{l}\text { Damping } \\
\text { ratio }\end{array}$ & $\begin{array}{l}\text { Natural } \\
\text { Frequency } \\
(\mathbf{H z})\end{array}$ & $\begin{array}{l}\text { Damping } \\
\text { ratio }\end{array}$ \\
\hline 1 & top & top & 2254 & 0.007 & 2339 & 0.008 \\
\hline 2 & down & down & 2336 & 0.003 & 2368 & 0.003 \\
\hline 3 & center & center & 2226 & 0.008 & 2254 & 0.010 \\
\hline
\end{tabular}

\section{Results And Discussion}

\subsection{Waveform characteristic of cutting vibration during the straight groove}

Figure 9 and Figure 10 show the time domain of the vibration measured during end milling of the straight groove for nitrided and unnitrided indexable end mills which include instantaneous values of acceleration as a function of time. It should be noted that Both waveforms describe cutting operation a few seconds before engagement and a few seconds after engagement.

By considering the waveform and the process of cutting, it is clear that the waveform can be divided into three sections marked as $\mathrm{A}, \mathrm{B}$, and $\mathrm{C}$ which corresponds to the three stages of the milling namely as cutin, steady-state cutting, and cut-out. Both mentioned waveforms Show that between each stage there is a peak value of acceleration vibration of dynamic interaction between the end mill and the workpiece and during the steady cut it has a lower peak value for acceleration.

From the time-domain waveform, we can extract different variables of acceleration, such as the mean value, Peak value and the root mean square (RMS), etc. According to Figure 9 and Figure 10, the peak value of acceleration along the $X, Y$, and the $Z$ directions within the steady cutting process for nitrided and unnitrided indexable end-mill are, respectively $3.85,4.20$, and 1.75 for unnitrided piece and 3.10, 3.40, 1.35 for the nitrided piece which shows that, during end-milling of the straight groove, the acceleration along with the three directions from the largest to the smallest, in turn, is perpendicular, feed and the axial direction in both cases. The reason is that the axial stiffness of the end mill is greater than the radial stiffness and the larger feed force along the X-axis increased cutting damping which suppresses the 
increase of feed acceleration. Thus, the largest acceleration vibration usually appears in the perpendicular direction in both nitrided and unnitrided end mills.

By calculating average RMS both for nitrided and unnitrided end mill in the steady-state stage we got the results described in Table 4 and the results imply a great improvement in different directions.

Table 4. Comparison between average RMS between nitrided and unnitrided tools during steady-state stage

\begin{tabular}{|l|l|l|l|}
\hline Direction & Unnitrided $\frac{m}{s^{2}}$ & Nitrided $\frac{m}{s^{2}}$ & Improvement (\%) \\
\hline Feed & 3.6 & 2.9 & 19.4 \\
\hline Axial & 1.7 & 1.2 & 29.4 \\
\hline Vertical & 4 & 3.2 & 20 \\
\hline
\end{tabular}

\subsection{Nitriding effect on the natural frequency}

By microhardness measurement, as shown in Figure 11 we determined the hardness distribution from the surface layer to the bulk. The first $20 \mu \mathrm{m}$ depth of the surface was white layer and Our measurement started at $50 \mu \mathrm{m}$ depth from the edge with an increment of $100 \mu \mathrm{m}$. It should be noted that nitriding was done at 500 degrees for 12 hours by substrate hardness of 32 HRC.

Based on the CNS 14288-G2272 standard [15], the effective depth of the nitrided specimen was calculated as the hardness value reaches the substrate hardness plus $50 \mathrm{HV}$, so in our case, the effective depth would be $300 \mu \mathrm{m}$. During nitriding operation, the nitrogen concentration starts from the maximum amount in the surface and decreases to the depth of cut, and Valdes [7] researches also demonstrate this behavior. For the sake of simplicity, we overestimated a constant young modulus of $300 \mathrm{GPa}$ for the effective nitrided layer and modeled the nitrided and unnitrided steel to investigate the effect of the nitrided layer on the natural frequency of the end mill.

As shown in Figure 12 and Figure 13 we modeled and meshed the used end mill in a straight groove by 1 $\mathrm{mm}$ mesh size and did modal analysis both for nitrided end mill and unnitrided layer by $0.3 \mathrm{~mm}$ hardened layer and the boundary condition for contact point by collect was assigned as fixed. The results for unnitrided and nitrided end mill are respectively 1540 and $1580 \mathrm{~Hz}$ which shows only 3 percent improvement which is ignorable.

By considering the FFT of these two end mills during straight groove in Figure 14 it is obvious that the natural frequency for both end mills remained the same. So, it can be concluded that the improvement in vibration peak and RMS is due to the increased damping ratio of the steel not improving tool rigidity so 
by nitriding our end mill nitriding has caused a significant improvement in its vibration behavior without increasing tool rigidity.

\section{Conclusion}

As shown above, during end milling the components of the acceleration vibration from largest to smallest are in turn the perpendicular, feed, and axial direction thus, the vibration in these directions should be lowered to get to better surface quality, less tool wear increased machining accuracy and upper productivity.

By running two nitrided and unnitrided end mills we demonstrated a significant improvement in vibration peaks and RMS by clarifying that nitriding led to a significant increase in damping ratio without changing tool rigidity relatively.

Based on the modal test, we found out almost 14 percent increase in the damping ratio of steel 1.7225 without any remarkable increase in natural frequency which meant nitriding did have a great effect on the samples to dissipate energy during vibration and to get better surface quality.

By interpreting the waveform extracted from the installed sensors during milling straight groove we got almost 23 decreases in the vibration RMS during steady-state cutting which showed how nitriding has affected decreasing tool vibration during operation.

\section{Declarations}

Funding information This research is financially supported by the Iranian Manufacturer of cutting tools, X-HOLD Company. The authors would also like to acknowledge X-HOLD for their support.

Conflicts of interests the authors declare that they have no conflicts of interests.

Availability of data and material the authors of this publication confirm that the data supporting the funding of this study are available as it's supplementary material.

Availability of data and material Authors of this publication confirm that the data supporting the findings of this study are available as Its supplementary materials.

Code availability Not applicable

Ethics approval The authors state this paper has not been submitted for consideration of publication to any other journal other than IJAMT. The authors further state that the contents of this paper comply with the rules of good scientific practices of the committee on Publication Ethics.

Consent to participate Not applicable 
Consent for publication The present paper does not require any consent to publish since all the figures, tables, and text are original.

Authors' contributions M.H. and E.I.: resources; M.H. and E.I.: investigation; M.H. and E.I.: data curation; M.H. and E.I.: writing original draft preparation; M.H. and E.I.: writing review and editing. M.H. and E.I., visualization; A.R. and B.M.: supervision. All of the authors have read and agreed to publish this version of the manuscript.

\section{References}

[1] D. Pye, Practical Nitriding and Ferritic Nitrocarburizing. ASM international, 2003.

[2] A. Nolan et al., ASM Handbook Volume 3 - Alloy Phase Diagrams, vol. 3. 1992.

[3] D. Kalliopi K. Aligizaki, Surface Engineering for Corrosion and Wear Resistance, vol. 51, no. 1. ASM International, 2004.

[4] A. Y. Beregovenko, V. G. Kaplun, A. P. Yakovlev, and I. N. Pastukh, "Influence of nitriding on damping properties of some metallic materials," Strength Mater., vol. 25, no. 8, pp. 604-609, Aug. 1993, doi: 10.1007/BF01151130.

[5] T. Nakanishi, T. Tsuchiyama, H. Mitsuyasu, Y. Iwamoto, and S. Takaki, “Effect of partial solution nitriding on mechanical properties and corrosion resistance in a type $316 \mathrm{~L}$ austenitic stainless steel plate," Mater. Sci. Eng. A, vol. 460-461, pp. 186-194, Jul. 2007, doi: 10.1016/j.msea.2007.01.024.

[6] S.-H. Yeh, L.-H. Chiu, and H. Chang, "Effects of Gas Nitriding on the Mechanical and Corrosion Properties of SACM 645 Steel," Engineering, vol. 03, no. 09, pp. 942-948, 2011, doi: 10.4236/eng.2011.39116.

[7] D. Fernández-Valdés, A. Meneses-Amador, G. A. Rodríguez-Castro, I. Arzate-Vázquez, I. Campos-Silva, and J. L. Nava-Sánchez, "Standing contact fatigue behavior of nitrided AISI 316L steels," Surf. Coatings Technol., vol. 377, no. May 2020, p. 124871, 2019, doi: 10.1016/j.surfcoat.2019.07.082.

[8] V. Parashar and R. Purohit, "Investigation of the effects of the Machining Parameters on Material Removal Rate using Taguchi method in EndMilling of Steel Grade EN19," Mater. Today Proc., vol. 4, no. 2, pp. 336-341, 2017, doi: 10.1016/j.matpr.2017.01.030.

[9] C. YUE, H. GAO, X. LIU, S. Y. LIANG, and L. WANG, "A review of chatter vibration research in milling," Chinese J. Aeronaut., vol. 32, no. 2, pp. 215-242, 2019, doi: 10.1016/j.cja.2018.11.007.

[10] B. B. Muhammad, M. Wan, J. Feng, and W. H. Zhang, "Dynamic damping of machining vibration: a review," Int. J. Adv. Manuf. Technol., vol. 89, no. 9-12, pp. 2935-2952, 2017, doi: 10.1007/s00170-0169862-z. 
[11] P. Huang, J. Li, J. Sun, and J. Zhou, "Study on vibration reduction mechanism of variable pitch end mill and cutting performance in milling titanium alloy," Int. J. Adv. Manuf. Technol., vol. 67, no. 5-8, pp. 1385-1391, 2013, doi: 10.1007/s00170-012-4575-4.

[12] Z. Dombovari and G. Stepan, "The effect of helix angle variation on milling stability," J. Manuf. Sci. Eng. Trans. ASME, vol. 134, no. 5, 2012, doi: 10.1115/1.4007466.

[13] R. Madoliat and S. Hayati, "Finite Element Analysis of a Frictionally Damped Slender Endmill," ASME Int. Mech. Eng. Congr. Expo. Proc., vol. 3, no. PARTS A, B, AND C, pp. 1931-1939, Oct. 2013, doi:

10.1115/IMECE2012-86920.

[14] Y. Yang, W. Dai, and Q. Liu, “Design and implementation of two-degree-of-freedom tuned mass damper in milling vibration mitigation," J. Sound Vib., vol. 335, pp. 78-88, 2015, doi:

10.1016/j.jsv.2014.09.032.

[15] CNS: 14288-G2272, 2006, 1-6.

\section{Figures}

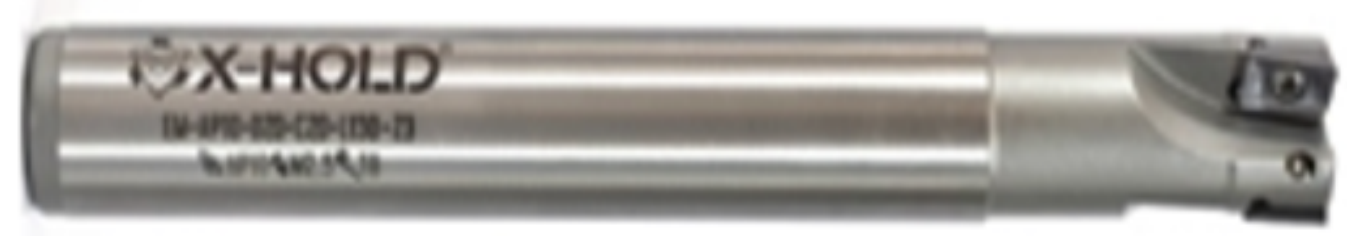

Figure 1

Indexable Endmill used in machining straight groove 


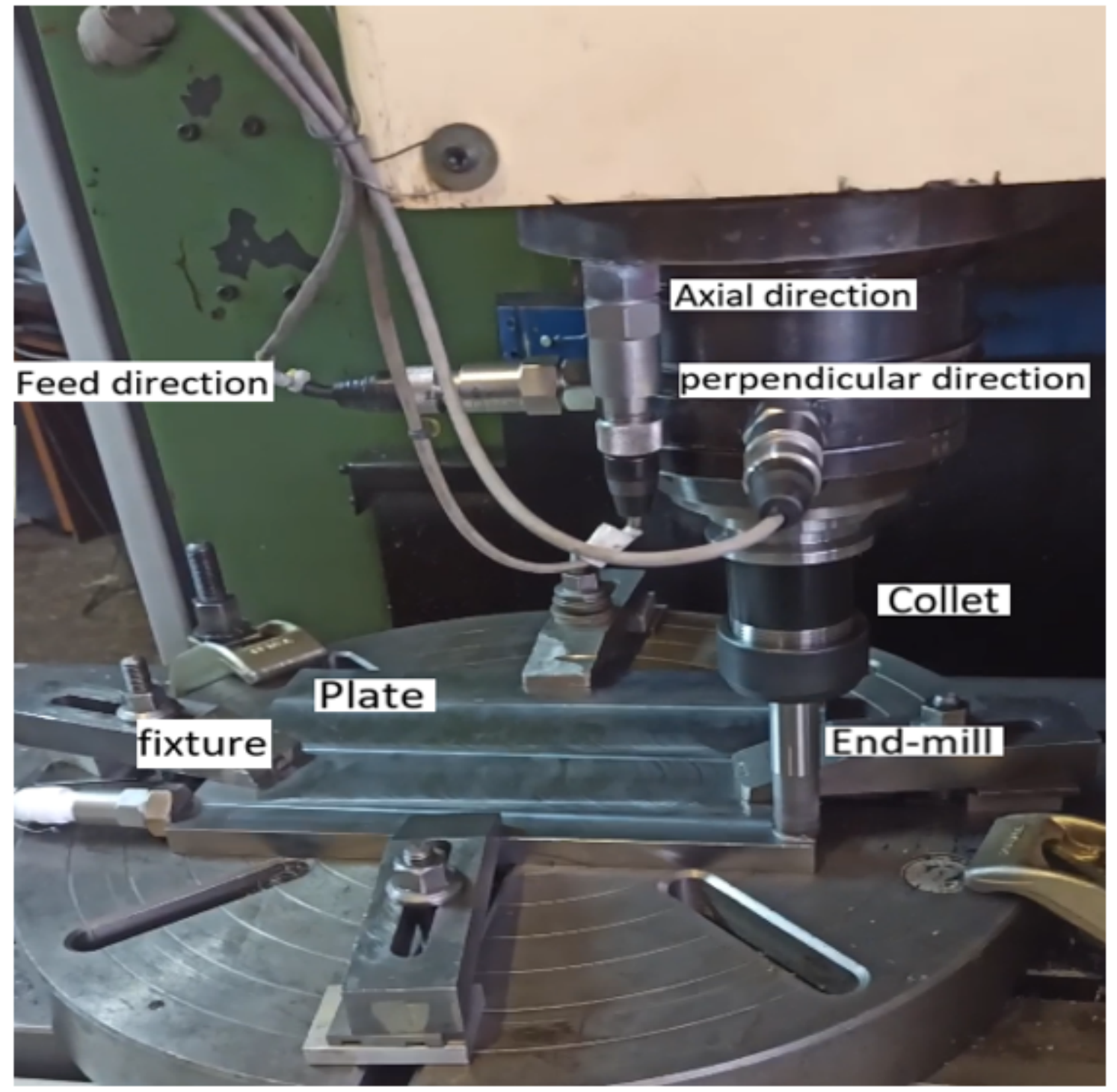

Figure 2

Test setup 


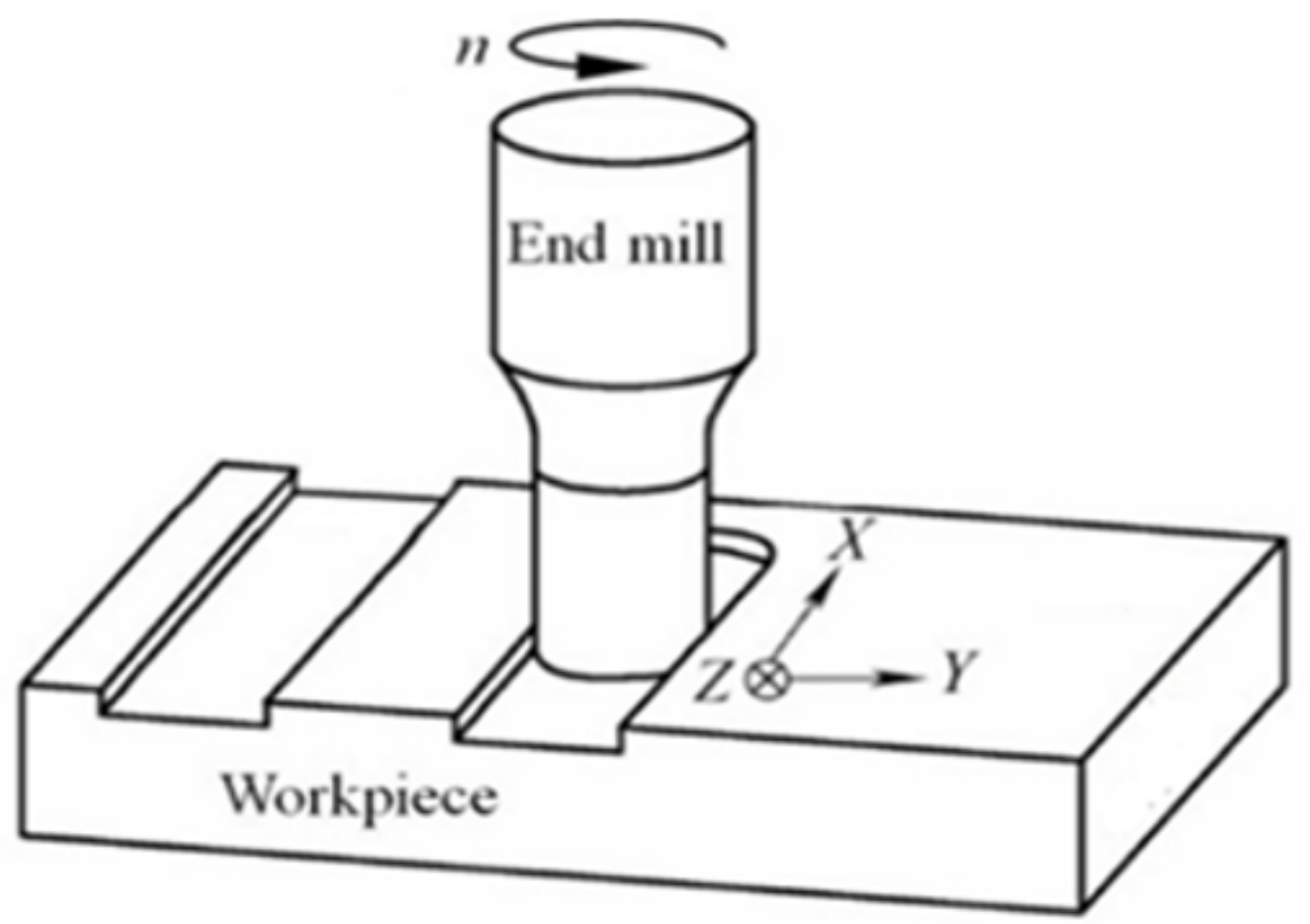

Figure 3

Detailed milling coordinate system. X, Y, and Z respectively correspond to feed, perpendicular and axial direction 


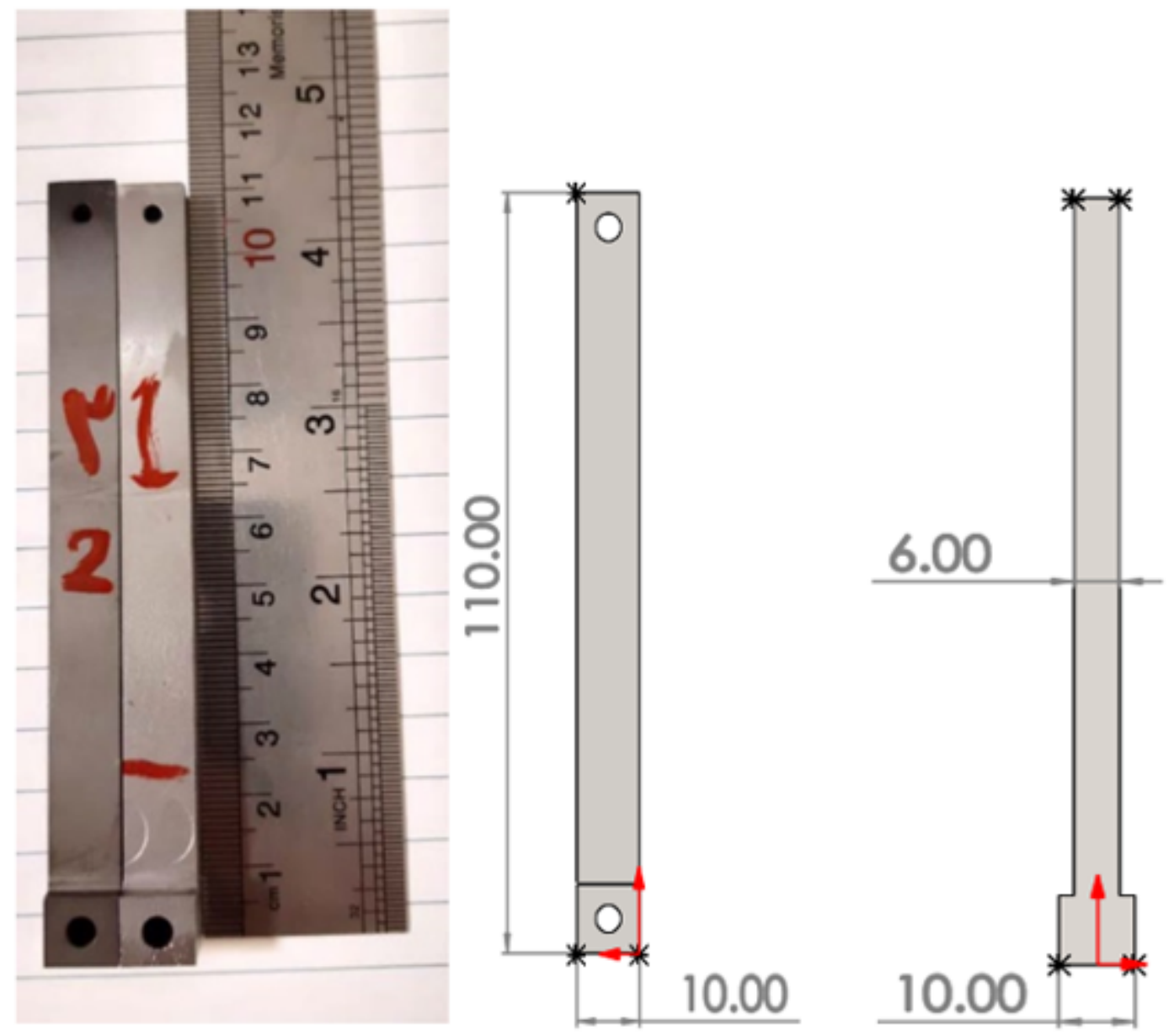

Figure 4

Samples description in the experiment 


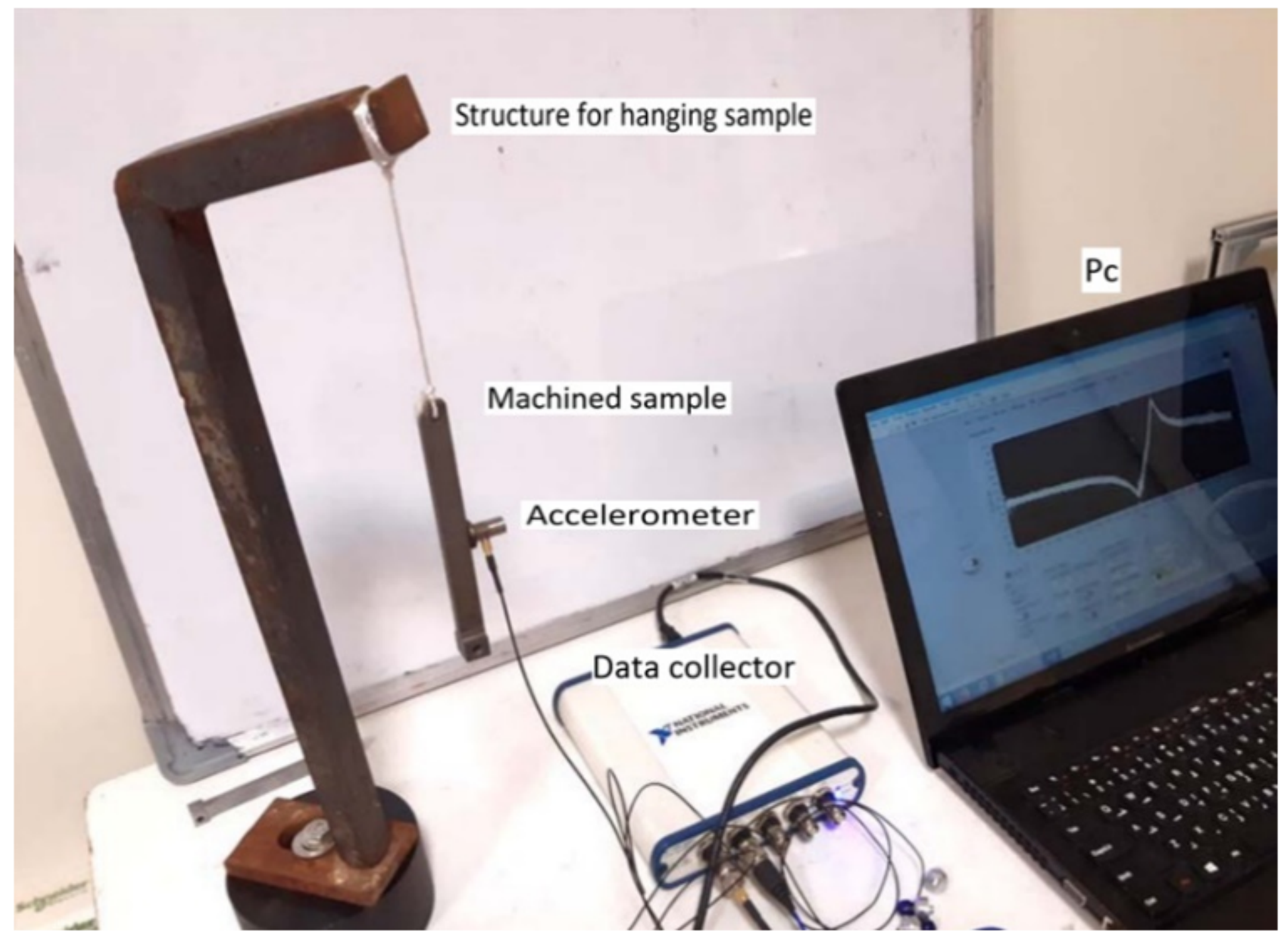

\section{Figure 5}

Modal test on the nitrided piece and unnitrided piece
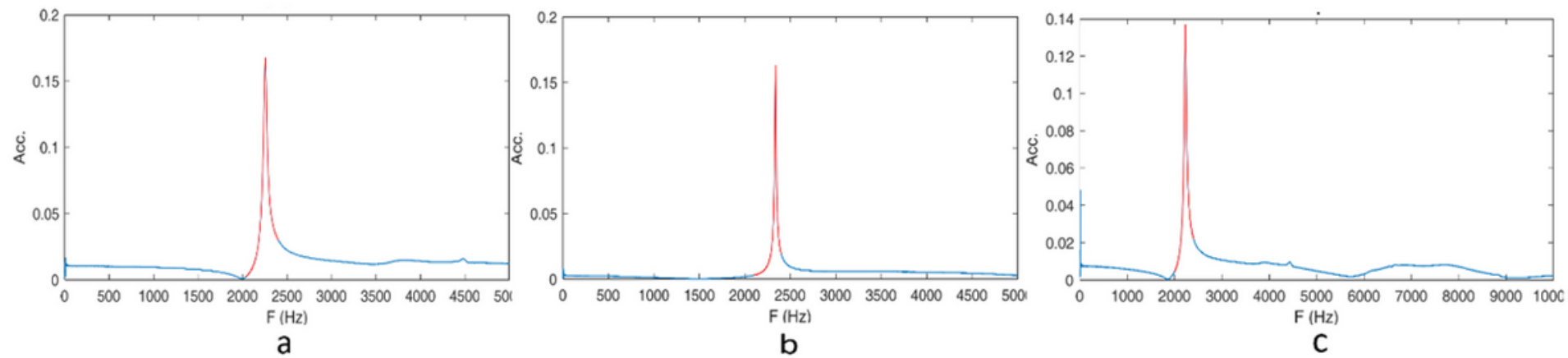

Figure 6

Acceleration frequency spectrum diagram for unnitrided sample. $a, b$ and c correspond to the top, down, and center respectively. 


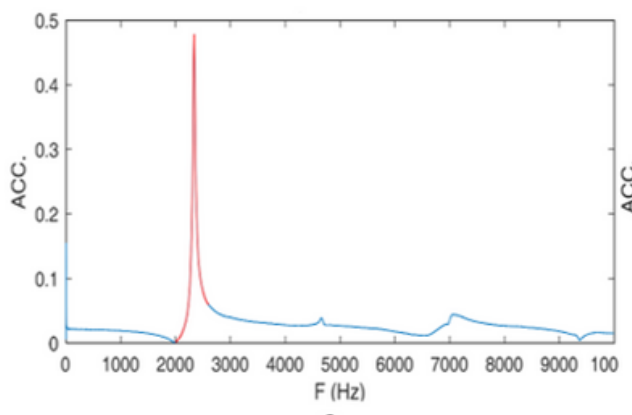

a

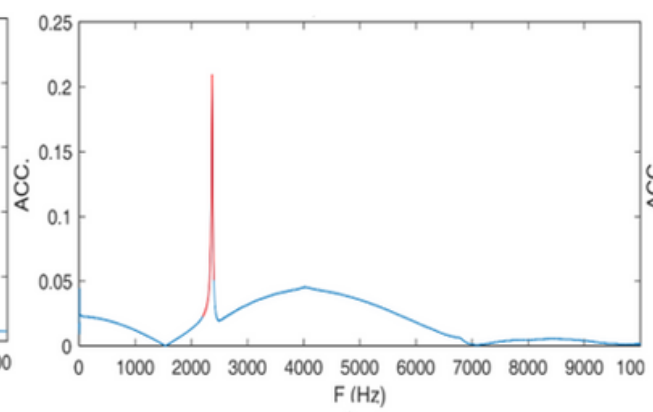

b

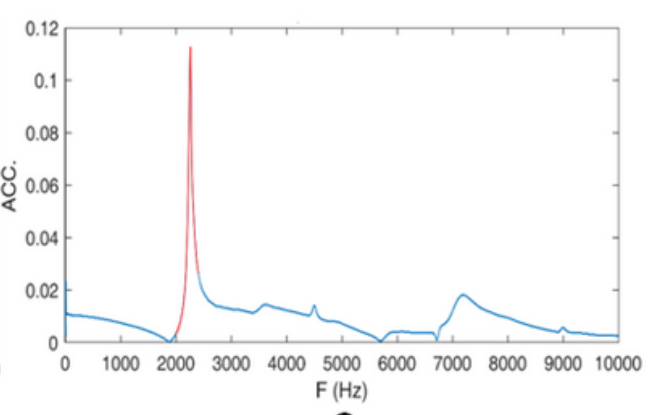

C

\section{Figure 7}

Acceleration frequency spectrum diagram for nitrided sample. $a, b$ and c correspond to the top, down, and center respectively.

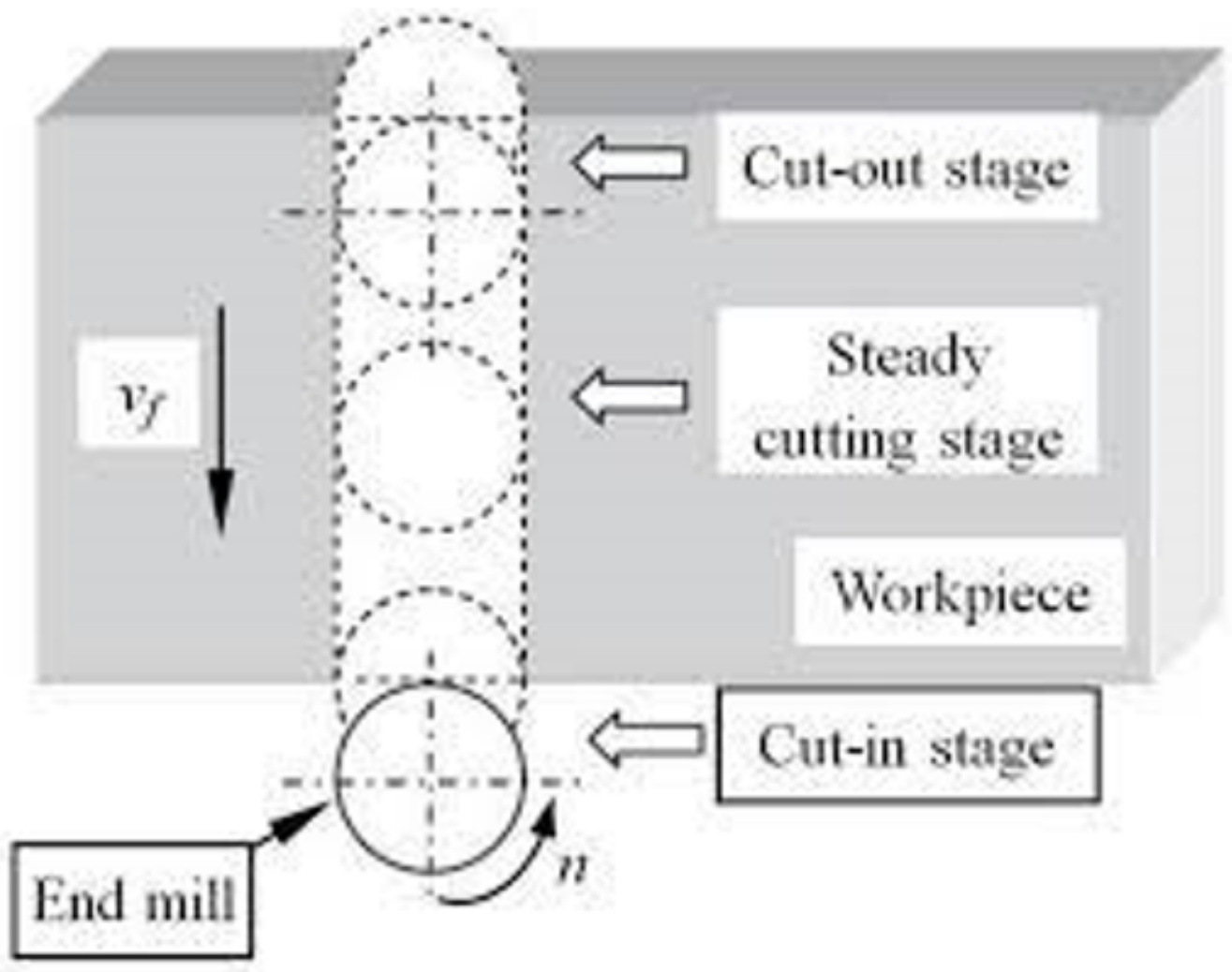

\section{Figure 8}

Three stages of end milling straight groove 


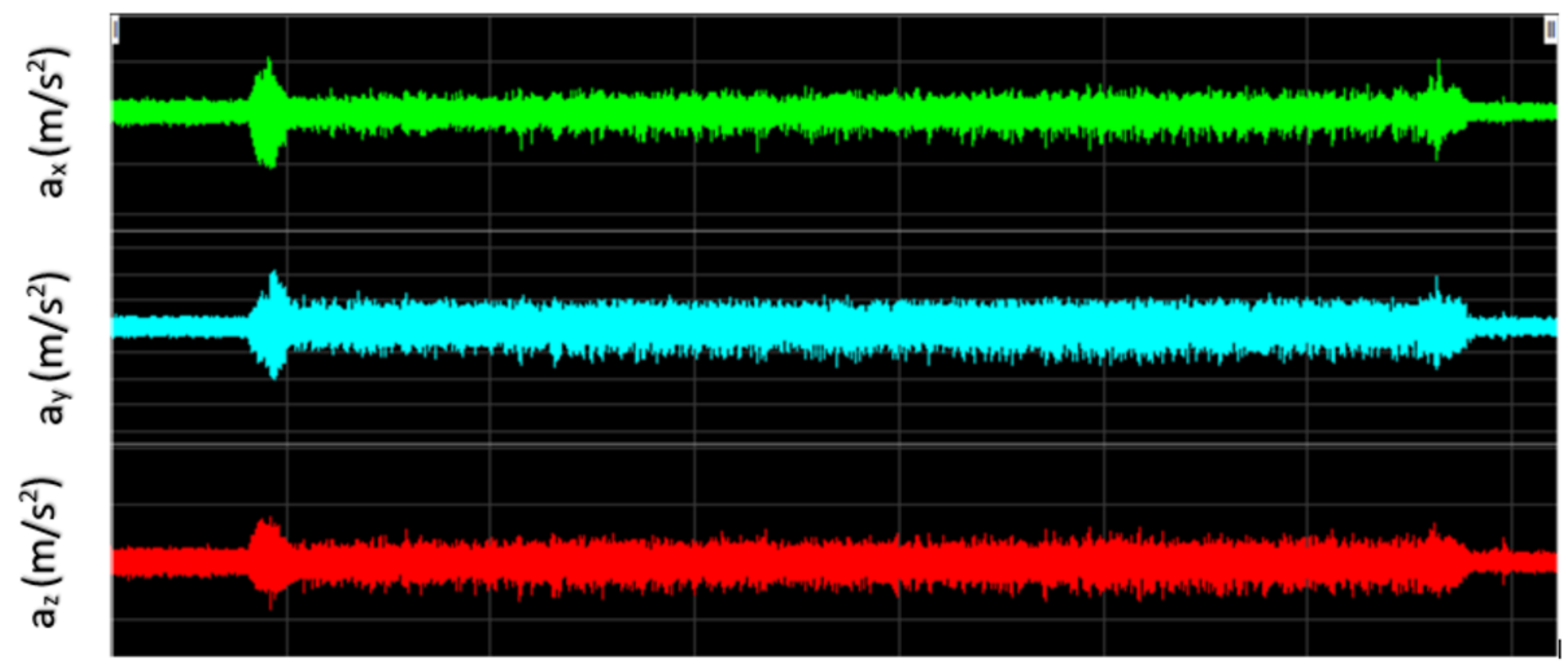

Figure 9

Time domain waveform of the cutting vibration of unnitrided indexable end mill

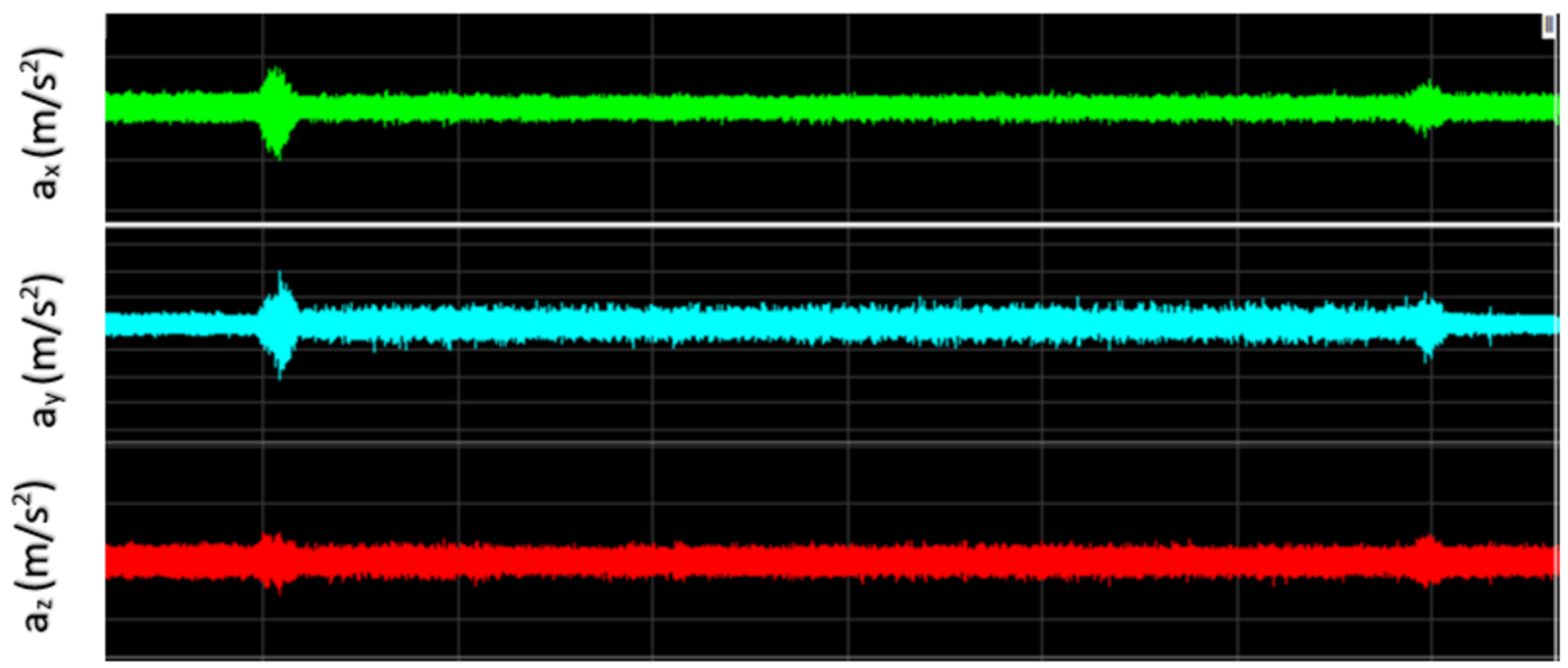

Figure 10

Time domain waveform of the cutting vibration of nitrided indexable end mill 


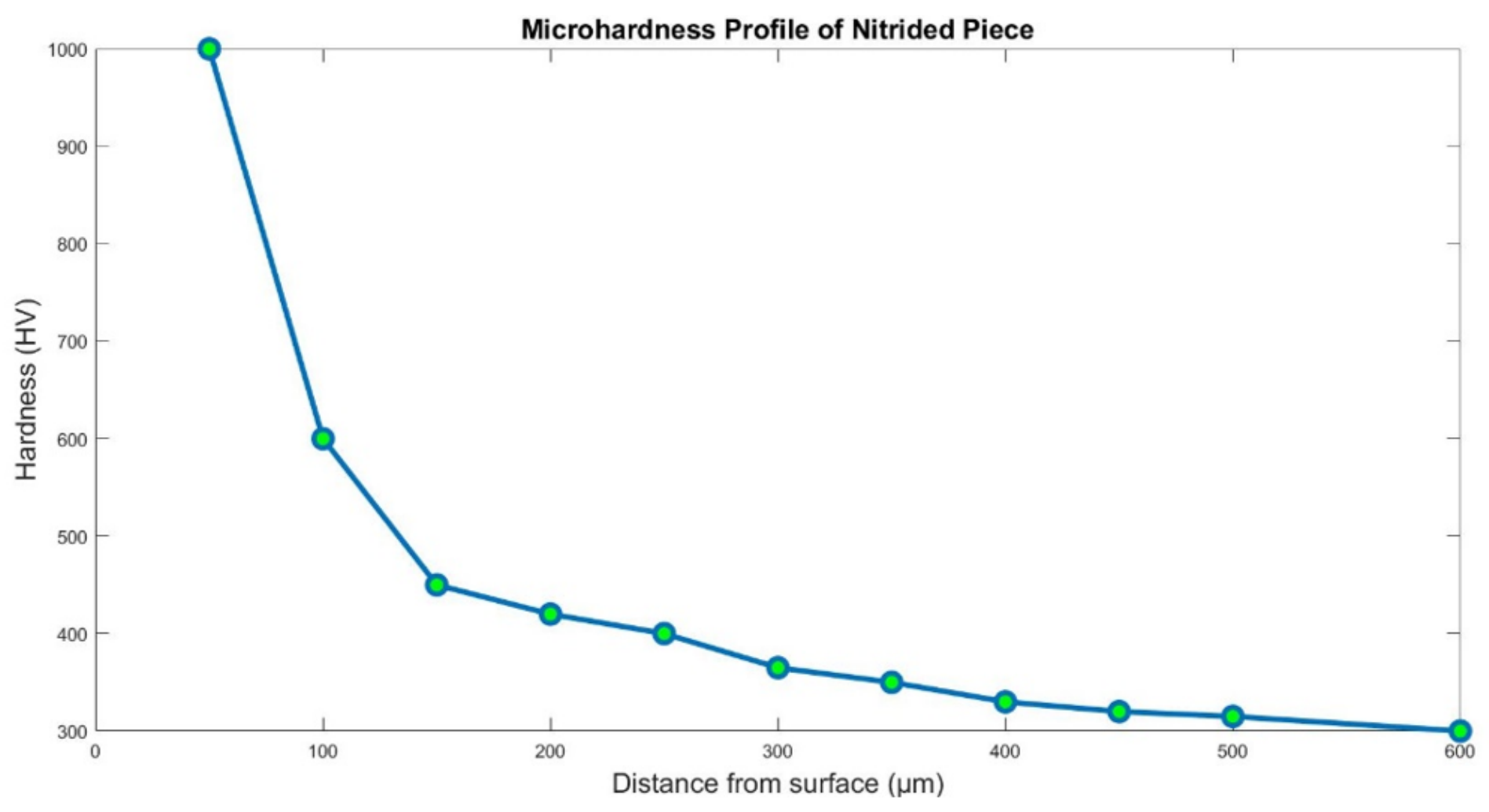

Figure 11

Microhardness profile of nitrided specimen nitrided at given condition

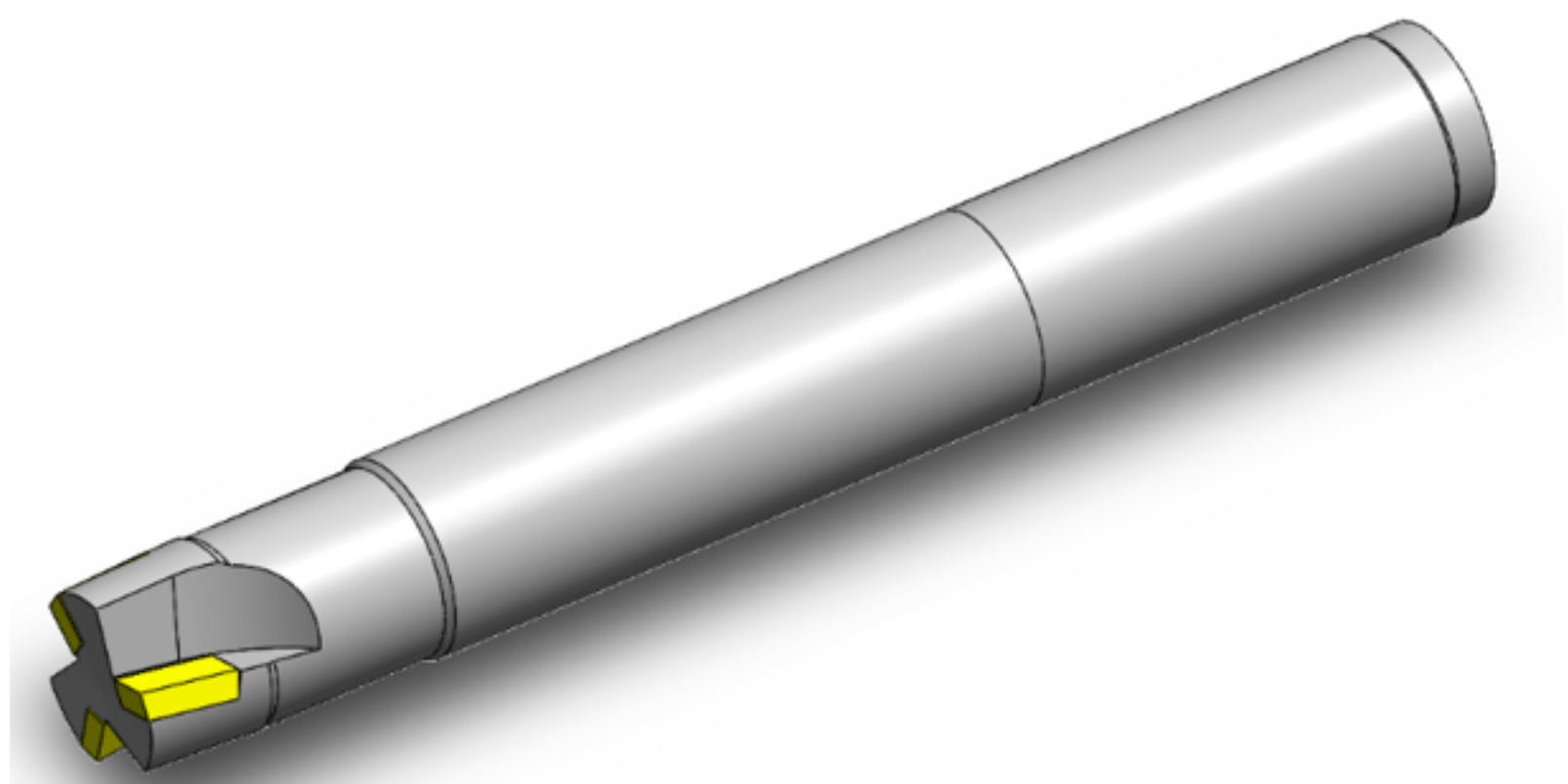

Figure 12

3D model of the used end mill in straight groove operation 


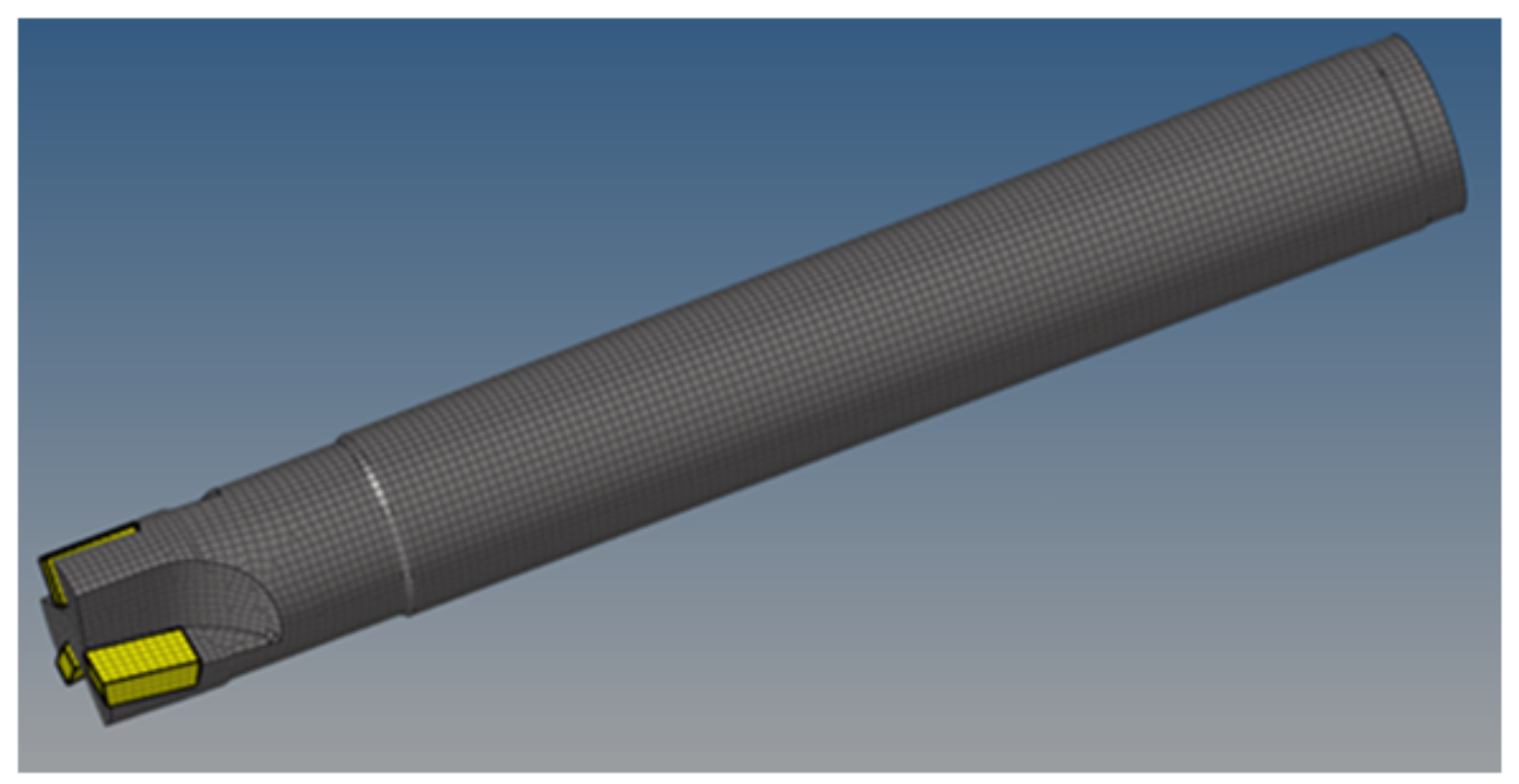

Figure 13

Meshing used end mill by $1 \mathrm{~mm}$ mesh size

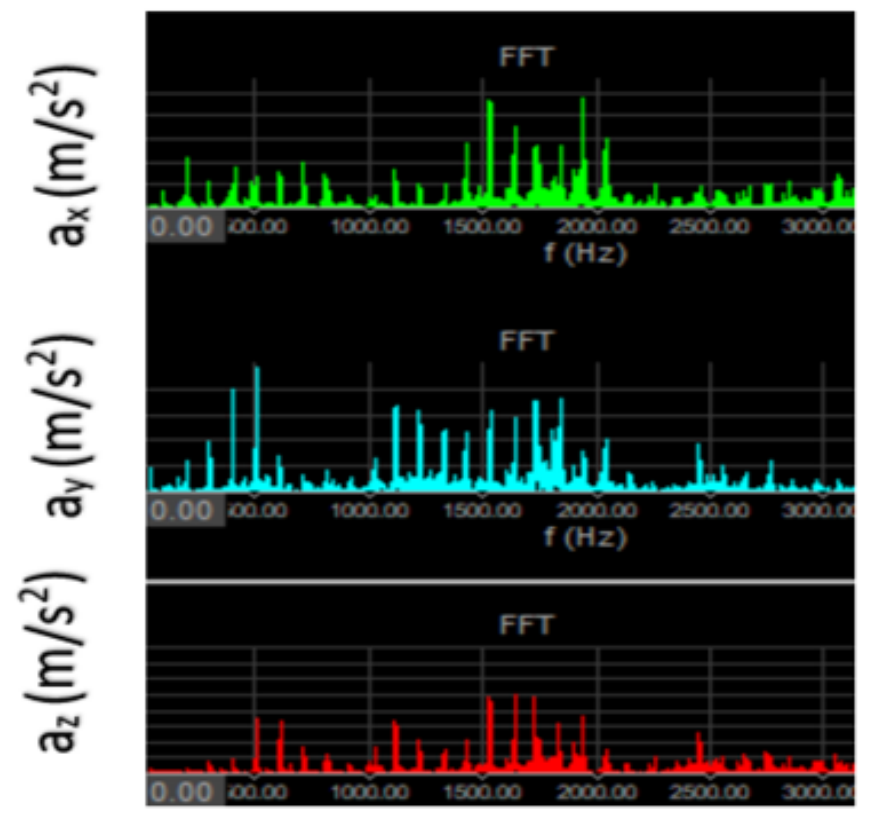

(a)

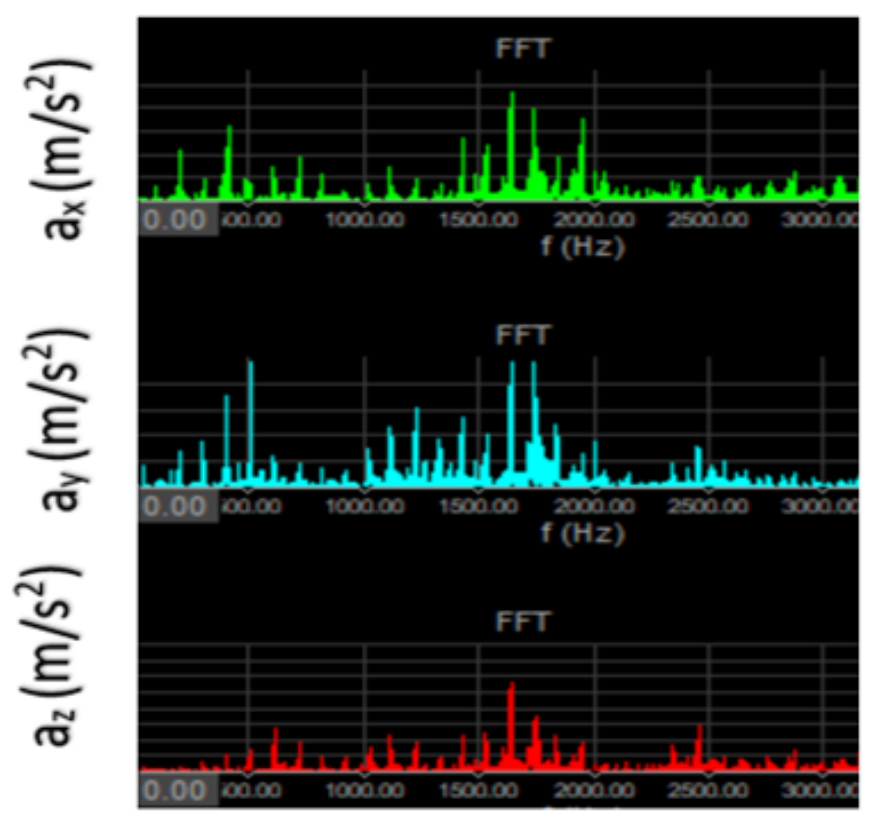

(b)

Figure 14

FFT of vibration waveform during end milling for- $a$ ) unnitrided- $b$ ) nitrided end mill 